\title{
Chlorophyll a Self-assembly in Polar Solvent-Water Mixtures $\dagger$
}

\author{
Radka Vladkova* \\ Institute of Biophysics, Bulgarian Academy of Sciences, Sofia, Bulgaria
}

Received 21 June 1999; accepted 4 October 1999

\section{ABSTRACT}

The conversion of chlorophyll $a(\mathrm{Chl} a)$ monomers into large aggregates in six polar solvents upon addition of water has been studied by means of absorption, fluorescence spectroscopy and fluorescence lifetime measurements for the purpose of elucidating the various environmental factors promoting $\mathrm{Chl} a$ self-assembly and determining the type of its organization. Two empirical solvent parameter scales were used for quantitative characterization of the different solvation properties of the solvents and their mixtures with water. The mole fractions of water $f_{1 / 2}$ giving rise to the midpoint values of the relative fluorescence quantum yield were determined for each solvent, and then various solvent-water mixture parameters for the $f_{1 / 2}$ values were compared. On the basis of their comparison, it is concluded that the hydrogen-bonding ability and the dipole-dipole interactions (function of the dielectric constant) of the solventwater mixtures are those that promote $\mathrm{Chl} a$ self-assembly. The influence of the different nature of the nonaqueous solvents on the $\mathrm{Chl}$ aggregation is manifested by both the different water contents required to induce $\mathrm{Chl}$ monomer $\rightarrow$ aggregate transition and the formation of two types of aggregates at the completion of the transition: species absorbing at $740-760 \mathrm{~nm}$ (in methanol, ethanol, acetonitrile, acetone) and at $667-670 \mathrm{~nm}$ (in pyridine and tetrahydrofuran). It is concluded that the type of Chl organization depends on the coordination ability and the polarizability (function of the index of refraction) of the organic solvent. The ordering of the solvents with respect to the $\mathbf{f}_{1 / 2}$ values-methanol $<$ ethanol $<$ acetonitrile $<$ acetone $<$ pyridine $<$ tetrahydrofuran-yielded a typical lyotropic (Hofmeister) series. On the basis of this solvent ordering and the disparate effects of the two groups of solvents on the $\mathrm{Chl} a$ aggregate organization, it is pointed out that the mechanism of Chl $a$ self-assembly in aqueous media can be considered a manifestation of the Hofmeister effect, as displayed in the lipid-phase behavior (Koynova et al., Eur. J. Biophys. 25, 261-274, 1997). It relates to the solvent ability to modify the bulk

\footnotetext{
*To whom correspondence should be addressed at: Institute of Biophysics, Bulgarian Academy of Sciences, Acad. G. Bonchev St., B1. 21, 1113 Sofia, Bulgaria. Fax: +359-2-9712493; e-mail: vladkova@obzor.bio21.bas.bg

$\uparrow$ Part of this work was presented at the 11 th International Congress on Photosynthesis, 17-22 August 1998, Budapest, Hungary.

(C) 2000 American Society for Photobiology 0031-8655/00 $\$ 5.00+0.00$
}

structure and to distribute unevenly between the Chlwater interface and bulk liquid.

\section{INTRODUCTION}

The process of photosynthesis in various organisms (plants, algae, photosynthetic bacteria) starts with the high efficient light collection by so-called antenna complexes. Chlorophyll $a(\mathrm{Chl} a) \neq$ and bacteriochlorophyll $c(\mathrm{Bchl} c)$ are the major antenna pigments in higher plants and in green photosynthetic bacteria, respectively. Their organization as high efficient light collectors is of crucial importance for the functioning of the overall photosynthetic unit. In contrast to green photosynthetic bacteria, where strong pigment-pigment interactions determine the organization of chlorosomal Bchl $c$ and $d(1)$, in higher plants the polypeptide amino acid residues bind and organize the antenna Chl $a$ and $b$ by specific and nonspecific interactions (2). Despite the fact that the structure of several Chl-protein complexes is known at near atomic resolution, the molecular mechanism for their assembly and structural stability remains unclear.

One of the reasons is that the mechanism for Chl selfassembly in aqueous media is also unclear. That such knowledge is of importance is evident by the same effects that medium composition has on both the chlorosomes (3) and Bchl $c$ and $d$ aggregates in aqueous media (4) or on chloroplast fragments (5) and $\mathrm{Chl} a$ aggregates in aqueous solvents (6). While the formation of Chl aggregates in various organic solvent-water mixtures is well documented (6-18), little is known about the contribution of the structure and properties of the medium for the assembly and stabilization of different $\mathrm{Chl}$ aggregate organizations in aqueous media. A study on the relationship between the $\mathrm{Chl}$ aggregation and solvent structure and properties can lead to an elucidation of the mechanism for Chl assembly and dissolution in aqueous media and consequently in the photosynthetic antenna complexes.

Despite the well-documented formation of Chl $a$ aggregates in organic solvent-water mixtures, there are only a few studies aimed at clarifying and quantifying the dependence of the process of Chl $a$ aggregation on the properties of the medium. In earlier studies, only the physical (nonspecific)

\footnotetext{
$\$$ Abbreviations: ACE, acetone: ACN, acetonitrile; Bchl, bacteriochlorophyll; Chl, chlorophyll; DMSO, dimethylsulfoxide; EtOH, ethanol; FWHM, full width at half maximum; $\mathrm{MeOH}$, methanol; PYR, pyridine; RR, resonance Raman; THF, tetrahydrofuran.
} 
parameters of the medium, the dielectric constant $\epsilon$ (19) and the molecular refraction and molecular polarization of the solvent-water mixtures (6) had been considered. Later studies focused mainly on the detailed description of the spectral properties of the different dimers and aggregates formed in particular polar solvent-water mixtures (15-18). The different spectral forms are ascribed to the bulk properties of the medium $(15,18)$ or to the specific Chl-solvent interactions characteristic of some particular solvents $(16,17)$. Uehara et al. $(16,17)$ found a correlation between solvent structure and selectively formed Chl $a$ aggregates absorbing at 683-695 $\mathrm{nm}$. Recently, Oba et al. (20) presented the solvent composition dependence of $\mathrm{Chl} a^{\prime}$ aggregation in aqueous methanol as a phase diagram. They concluded that the Chl $a^{\prime}$ aggregation is similar to a phase separation (a micellization) of nonionic surfactant in water, based on the similarity in critical behavior. However, if the different specific and nonspecific solvation properties of the aqueous medium are not taken into account, and most importantly are not quantitatively described, it is difficult to evaluate the main principles governing the process of $\mathrm{Chl}$ association in various aqueous media.

In view of the difficulties applying theoretical expressions for calculating all interactions in three-component systems, another route to establishing the role of the medium is to use some of the empirical solvent scales as quantitative measures of both specific and nonspecific solvating properties. There are a number of empirical parameters that take into account all solute-solvent interactions at a microscopic level $(21,22)$. Moreover, several empirical parameters have already been successfully applied in model studies on Chl $a$ and Bchl $a$ (23-25). The parametrization of various aqueous media should simplify evaluation of the common solvent effect on Chl aggregation in different systems.

To our knowledge, the present work is the first attempt to use empirical solvent parameters for quantitative description of the different specific and nonspecific solvation properties of the medium during the process of Chl $a$ self-assembly in six polar solvent-water mixtures. Based on this, it was possible to correlate the process of Chl aggregation as well as the type of aggregates formed at the completion of transition with the solvent parameters. The established correlation allowed us to consider the polar solvent effect on Chl $a$ aggregation in aqueous media as a manifestation of the Hofmeister effect, just as it is displayed concerning the structural stability of two other biomolecular assemblies: proteins and lipids. Based on the proposed mechanism, the solvent effect studied here is directly connected to the spectra-structurefunction relationship in vivo.

\section{MATERIALS AND METHODS}

Materials. Chlorophyll $a$ was purchased from Sigma Chemical Co. (catalogue no. C-6144) and used without further purification. All solvents used were freshly dried and distilled prior to use. Methanol $(\mathrm{MeOH})$ and ethanol (EtOH) (p.a.) were allowed to stand over $\mathrm{CaO}$, then dried by $\mathrm{Mg}$ turnings; acetone (ACE), acetonitrile (ACN) and carbon tetrachloride $\left(\mathrm{CCl}_{4}\right)$ (Fluka) were allowed to stand over $\mathrm{CaCl}_{2}$, and pyridine (PYR) and tetrahydrofuran (THF) (Merck) over solid $\mathrm{NaOH}$ and $\mathrm{KOH}$, respectively. After that, the solvents were filtered, distilled and stored over activated $4 \AA$ molecular sieves (Merck). Water was doubly distilled.

Sample preparations. The stock solution of $1 \mathrm{mg} \mathrm{Chl} a$ in $10 \mathrm{~mL}$
$\mathrm{CCl}_{4}$ was prepared and kept in the dark at $-20^{\circ} \mathrm{C}$. For every series of solvent-water mixtures, equal amounts of the stock solution were put into test tubes and $\mathrm{CCl}_{4}$ was evaporated with a stream of dry nitrogen. The thin films of Chl $a$ were dissolved in the desired amount (vol\%) of the solvent of interest, and then the required amount of water was added. The closed test tube containing the solution was then shaken by hand several times. The concentration of Chl $a$ was determined by its optical density (absorbance) in the red band peak using the molar extinction coefficient in each single solvent (26). The maxima of the absorption bands and their relative intensities were in good agreement with the published values for these solvents. For every series of solvent-water mixture the concentration of Chl was the same, usually in the range of 2.7-2.9 $\times$ $10^{-6} M$. The studied concentration range was $2.7-5.7 \times 10^{-6} \mathrm{M}$.

Absorption and fluorescence measurements. Absorption measurements were performed on a Specord UV/visible double-beam spectrophotometer (Carl Zeiss, Germany). The spectra are presented as absorption, $1-\mathrm{T}(\mathrm{T}=$ transmission), in order to better see the details of the spectral transformations. Identical results are observed for a concentration of 2.7 or $5.7 \times 10^{-6} \mathrm{M}$.

The fluorescence spectra were recorded on a Perkin-Elmer MPF 44B spectrofluorometer at right angle with respect to the excitation. The excitation wavelength was $430 \mathrm{~nm}$; the spectral bandwidths were $4 \mathrm{~nm}$. The relative fluorescence quantum yields $\phi^{\mathrm{w}} / \phi^{\circ}$ of Chl $a$ in solvent-water mixtures versus that in the pure organic solvent were determined by dividing the ratio of the integrated fluorescence intensities (600-770 $\mathrm{nm}$ spectral range) of both samples by the ratio of their absorption, $(1-\mathrm{T})$, at the excitation wavelength. The experimental error in the quantum yield was estimated to be $10 \%$. Fluorescence lifetime measurements were done using a laser pulse fluorometer LIF 200 (ZWG, Berlin; excitation source: nitrogen laser $\left[\lambda_{\text {exc }}=337.1 \mathrm{~nm}\right.$, pulse duration $\left.\approx 500 \mathrm{ps}\right]$; detection system: photodiodes with boxcar integrator, instead of monochromator-only cutoff filters could be utilized). The apparatus is described in detail in Dähne et al. (27). Laser pulse intensity was around $1 \times 10^{14}$ photons $/ \mathrm{cm}^{2}$. The fluorescence lifetimes were determined by using the standard deconvolution procedure.

Each sample was measured $1 \mathrm{~min}$ after preparation at appropriate time intervals until temporal evolution in the spectra was accomplished. Measurements were carried out in closed $1 \mathrm{~cm}$ quartz cuvettes at $25^{\circ} \mathrm{C}$, because data on the used solvent and solvent-water mixture parameters are available in the literature at this temperature.

Parameters of the solvents and solvent-water mixtures. The refractive index (n) measurements of the solvents and solvent-water mixtures were made at $25^{\circ} \mathrm{C}$ with an Abbe-type refractometer from Carl Zeiss Jena.

The interpolated values of the dielectric constant $\epsilon$ for different solvent-water mixtures were taken from the available literature data (see references in Table 1) with the exception of $\mathrm{ACN}$-water mixtures. They were calculated using Eq. 22 in Hasted (31).

The values of the solvent polarity parameter $\mathrm{E}_{\mathrm{T}}(30)$ for the mixtures were taken from the literature (see references in Table 1), except for the ACN- and THF-water mixtures. Knowing that the $E_{T}(30)$ values of $A C N$ were intermediate between those of EtOH and ACE (22), the intermediate value between the EtOH- and ACEwater mixtures (33) at the respective vol\% water was taken for the ACN-water mixture. The same was done for THF-water using the established similarity between THF and dioxane (34); we took the values of $\mathrm{E}_{\mathrm{T}}(30)$ for the latter solvent in mixture with water that is known (33).

The parameters electrophilicity (E) and nucleophilicity (B) of the solvent-water mixtures were calculated as additive functions of their mole fractions, according to Palm (32).

\section{RESULTS AND DISCUSSION}

\section{Chl $a$ monomer $\rightarrow$ aggregate transition}

For the purpose of the present work, six polar solvents were selected that are of very different chemical nature and cover a wide range of values of medium physical parameters such as index of refraction and dielectric constant (Table 1). As is shown in Table 1 these solvents give rise to four types of 
Table 1. Characterization of Chl $a$ solutions: type of specific solvation of Chl $a$, index of refraction $(n)$ and dielectric constant $(\epsilon)$, Dimroth and Reichardt's solvent polarity parameter $\mathrm{E}_{\mathrm{T}}(30)$ (in $\mathrm{kcal} / \mathrm{mol}$ ) and Koppel and Palm's empirical solvent parameters: polarity $(Y)$, polarizability $(P)$, electrophilicity $(E)$ and nucleophilicity $(B)$

\begin{tabular}{|c|c|c|c|c|c|c|c|c|}
\hline $\begin{array}{c}\text { Sol- } \\
\text { vent* }\end{array}$ & $\begin{array}{l}\text { Type of } \\
\text { solvate } \dagger\end{array}$ & $n \neq$ & $\epsilon \S$ & $\mathrm{E}_{\mathrm{T}}(30) \|$ & $Y$ & $P$ & $E \rrbracket$ & $B \mathscr{I I}$ \\
\hline Water & & 1.3330 & 78.48 & 63.1 & 0.9627 & 0.2057 & 21.8 & 156 \\
\hline $\mathrm{MeOH}$ & $\mathrm{L}_{2} \mathrm{H}$ & 1.3285 & 32.66 & 55.5 & 0.9134 & 0.2032 & 14.9 & 218 \\
\hline EtOH & $\mathrm{L}_{1} \mathrm{H}$ & 1.3614 & 24.3 & 51.9 & 0.8859 & 0.2215 & 11.6 & 235 \\
\hline $\mathrm{ACN}$ & $\mathrm{L}_{1}$ & 1.3440 & 36.0 & 46.0 & 0.9211 & 0.2118 & 5.2 & 160 \\
\hline ACE & $\mathrm{L}_{1}$ & 1.3589 & 19.1 & 42.2 & 0.8578 & 0.2201 & 2.1 & 224 \\
\hline PYR & $\mathrm{L}_{2}$ & 1.5101 & 13.06 & 40.2 & 0.8008 & 0.2991 & 0 & 472 \\
\hline THF & $\mathrm{L}_{2}$ & 1.4076 & 7.39 & 37.4 & 0.6805 & 0.2465 & 0 & 287 \\
\hline
\end{tabular}

*Arranged by decreasing $\mathrm{E}_{\mathrm{T}}(30)$ values (fourth column).

$\dagger \mathrm{L}_{\mathrm{i}}$ denotes the coordination number $(=\mathrm{i}+4)$ of the $\mathrm{Mg}$ atom; $\mathrm{L}_{\mathrm{i}} \mathrm{H}$ denotes additional hydrogen bonds with the keto carbonyl group of Chl $a(23,24,28,29)$.

\pm Measured at $25^{\circ} \mathrm{C}$.

$\S$ Values at $25^{\circ} \mathrm{C}$ taken from Landolt-Börnstein (1959) Vol. II/6, pp. 750-753, Springer-Verlag, Berlin for water, MeOH, ACE and THF; for EtOH from Åkerlöf (30); for ACN from Gutman (21), p. 148, and for PYR from Hasted (31), p. 424.

$\|$ At $25^{\circ} \mathrm{C}$ from Reichardt (22), pp. 270-271.

q[From Palm (32), pp. 333-334.

specific solvates of monomeric Chl $a$ that also imitate different in vivo pigment environments. The parameters used for the quantitative characterization of different specific and nonspecific solvation properties of the solvents and water are also listed in Table 1 . In order to assess the role of the different properties of the medium on $\mathrm{Chl}$ association only, the concentration of Chl $a$ was low and kept constant in all solvents and solvent-water mixtures. By varying the molar ratio of solvents and water that are miscible in all proportions, it was possible to change all medium parameters and thus to induce the association of $\mathrm{Chl}$ molecules. Figure 1 shows the effect of the increase of water content on the relative fluorescence quantum yield $\phi^{\mathrm{w}} / \phi^{\circ}$ (normalized with respect to those of monomeric $\mathrm{Chl} a$ in the respective nonaqueous solvent). These curves were used as a diagnostic tool for the degree of Chl monomer $\rightarrow$ aggregate transition.

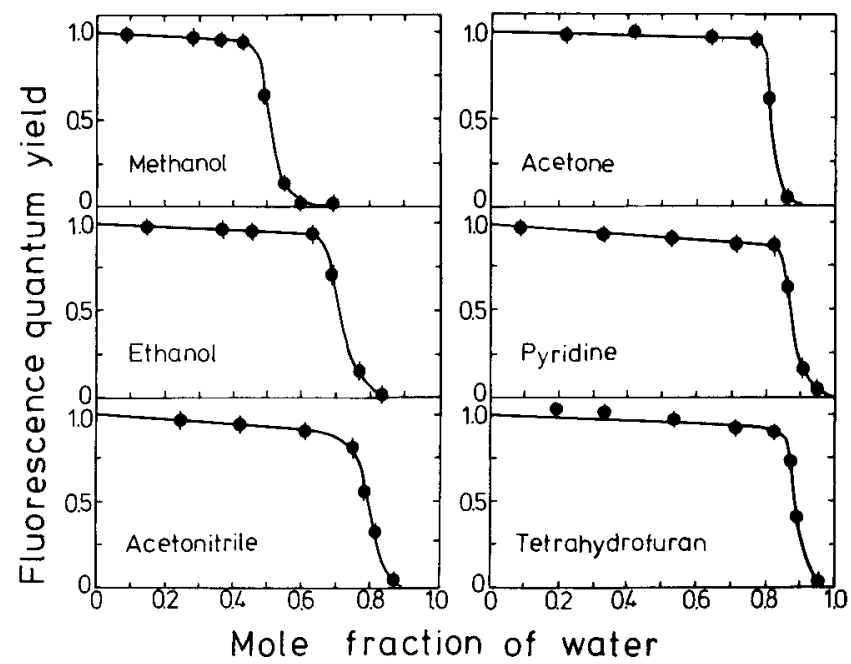

Figure 1. Normalized fluorescence quantum yield of Chl $a$ (relative to the respective nonaqueous solvent) in different solvent-water mixtures as a function of the mole fractions of water. The concentration of Chl $a$ was kept low and constant $\left(2.7-2.9 \times 10^{-6} M\right)$, while the solvent/water ratio was varied.
The grounds to use $\phi^{\mathrm{w}} / \phi^{\mathrm{o}}$ as a measure of the fraction of the monomeric $\mathrm{Chl}$ molecules in the mixtures were (1) by definition it directly yields the number of fluorescing molecules; (2) these fluorescing molecules are the monomeric Chl $a$ because the excitation is at $430 \mathrm{~nm}$, i.e. not at the wavelength longer than the Soret absorption maximum, a region for excitation of aggregated Chl $a$ (20); (3) it is well known that aggregated forms of Chl $a$ in dilute polar solvent-water mixtures are practically nonfluorescent or nearly so at room temperature $(9,12)$ and the possible part of their fluorescence ( $\leq 1 \%$ with respect to the monomeric ones) is included in the error limits connected with the calculation of the relative quantum yields (relative error at the highest mole fractions of water $\pm 10-15 \%)$.

Figure 1 demonstrates that the effect of water on the relative quantum yield of $\mathrm{Chl} a$ can be divided into three zones. In zone I, the linearly approximated part of the curves, the changes in $\phi^{\mathrm{w}} / \phi^{\circ}$ are small and continuous depending on the pure solvent. These changes are ascribed to changes in the dielectric constant of the solutions of the monomeric Chl $a$ (13) and also to changes in the type of specific solvation of monomeric Chl $a(14,35)$ (see below). In zone II, termed here the transition zone, there is an abrupt decrease of fluorescence quantum yield, i.e. a strong decrease in the number of monomeric Chl $a$ with an increase in water content. The mole fractions of water at which the quenching of Chl $a$ fluorescence starts, i.e. the onset of the monomer $\rightarrow$ aggregate transition, in each of the solvent-water mixtures are different and increase in succession $\mathrm{MeOH}<\mathrm{EtOH}<\mathrm{ACN}$ $<$ ACE $<$ PYR $<$ THF. This result indicates that the different solvents exert different association power on Chl $a$ in mixtures with water and will be discussed later. In zone III, there is no fluorescence, i.e. the transition is already completed, and all the monomeric $\mathrm{Chl}$ exists in aggregate form. In this study, the effect of solvent-water composition on the aggregation of Chl $a$ is examined until the full quenching of the monomeric $\mathrm{Chl}$ fluorescence is accomplished. As a whole, the values of the mole fractions of water, marking the transition zone, are in accordance with previous studies $(6,12,13,15)$. 
Table 2. Mole fractions of water $f_{1 / 2}$ in different solvent-water mixtures corresponding to the midpoint value of the relative fluorescence quantum yield curves of Chl $a$, established from Fig. 1

\begin{tabular}{|c|c|c|c|c|}
\hline $\begin{array}{c}\text { Sol- } \\
\text { vent* }\end{array}$ & $\begin{array}{c}f_{1 / 2} \\
( \pm 0.01)\end{array}$ & $\begin{array}{c}\text { Concentration } \\
\text { of water } \dagger \\
\text { (vol/vol) } \%\end{array}$ & $n_{1 / 2} \ddagger$ & $\epsilon_{1 / 2} \S$ \\
\hline $\mathrm{MeOH}$ & 0.51 & $31.6 \pm 0.9$ & $1.3423 \pm 0.0002$ & $50.4 \pm 0.4$ \\
\hline EtOH & 0.72 & $44.3 \pm 1.2$ & $1.3608 \pm 0.0002$ & $50.5 \pm 0.5$ \\
\hline $\mathrm{ACN}$ & 0.79 & $56.3 \pm 1.5$ & $1.3462 \pm 0.0003$ & $60.1 \pm 0.6$ \\
\hline $\mathrm{ACE}$ & 0.82 & $52.8 \pm 1.7$ & $1.3583 \pm 0.0006$ & $53.7 \pm 1.2$ \\
\hline PYR & 0.87 & $59.9 \pm 2.2$ & $1.4088 \pm 0.0040$ & $55.5 \pm 1.0$ \\
\hline THF & 0.88 & $61.9 \pm 2.3$ & $1.3684 \pm 0.0020$ & $52.2 \pm 1.8$ \\
\hline
\end{tabular}

*See footnote *, Table 1 .

$\dagger$ Calculated from $f_{1 / 2} \pm \mathrm{SD}$.

$\ddagger$ Measured at $25^{\circ} \mathrm{C}$.

$\S$ See footnote $\S$ in Table 1, except for ACN. Its value was calculated using Eq. 22 in Hasted (31), p. 412.

In order to assess which properties of the medium promote Chl association, the midpoints of the fluorescence quenching curves with respect to the mole fractions of water were estimated. At that point, the fraction of monomeric Chl $a$ is the same for all mixtures, irrespective of the cooperativity of the transition (7) and the intermediate small aggregates (dimers, trimers, etc.) formed during the transition. The idea was to find a characteristic parameter of the medium that has similar values in all different solvent-water mixtures at the midpoint of the transition. In this way we intended to decipher the interactions responsible for Chl $a$ self-assembly.

Table 2 summarizes the mole fraction of water $f_{1 / 2}$ values for all mixtures that correspond to the midpoint of each $\phi^{\mathrm{w}} /$ $\phi^{\circ}$ curve, presented in Fig. 1 . The values of $f_{1 / 2}$ in the different mixtures increase in the same order as at the onset of the transition.

The quantitative characterization of the different medium properties for the $f_{1 / 2}$ mixtures is done by the values of their physical constants (Table 2) and empirical parameters (Table 3 ). The comparison of the relative deviations of the weighted mean values (36) for all parameters, as well as the sum of their relative deviations (Table 3 ) shows that these devia- tions are smallest for the $\mathrm{E}_{\mathrm{T}}(30)$ parameter and for two of the four-parametric scale of Koppel and Palm, $\mathrm{Y}_{1 / 2}$ and $\mathrm{E}_{1 / 2}$. Taking into account that these deviations are within the same range as the maximum error limits imposed by the $f_{1 / 2}$ values ( $\leq 4 \%$, Table 2), it is clear that the values of the $\mathrm{E}_{\mathrm{T}}(30)$ parameter, and those of the $Y_{1 / 2}$ and the $E_{1 / 2}$ parameters can be taken as equal within the experimental error for all six mixtures. Note also that the pure solvents have very different empirical parameters (Table 1). Thus, irrespective of the kind of polar solvent, the monomer $\rightarrow$ aggregate transition takes place at certain values of the solvent parameters $\mathrm{E}_{\mathrm{T}}(30), \mathrm{Y}$ and $\mathrm{E}$. This result is convincing evidence that the properties of the medium, characterized by these parameters, are of primary importance for Chl $a$ association in aqueous media.

\section{How the medium promotes $\mathrm{Chl} a$ self-assembly}

The empirical parameter polarity $\mathrm{E}_{\mathrm{T}}(30)$ from the single parametric approach of Reichardt and Dimroth as described by Reichardt in (22) is essentially a scale reflecting dipoledipole interactions (expressed by the function of the dielectric constant, $\epsilon$ ) with the addition of the hydrogen-bonding ability of the solvent (37). The $\mathrm{E}_{\mathrm{T}}(30)$ polarity scale is one of the various empirical scales introduced to characterize the solvation ability of solvents. In view of the complexity of solute-solvent interactions, it is beneficial to correlate the association of Chl $a$ molecules in aqueous solutions with a single parameter.

The second quantitative approach used here gives the complete description of all specific and nonspecific solvating abilities of the solvents. It is noteworthy that the exact same two properties characterized by the $\mathrm{E}_{\mathrm{T}}(30)$ parameter are the properties characterized quantitatively by the parameters $\mathrm{Y}$ and $\mathrm{E}$ from the four-parametric approach of Koppel and Palm as described by Palm in (32). The nonspecific polarity parameter $\mathrm{Y}$ measures solvent polarization used in the form of the Kirkwood function $(\epsilon-1) /(\epsilon+2)$. Y characterizes the polarity of the solvent in terms of dipole moments. The larger the polarity of the medium, the larger the average dipole moment and the better the alignment of molecules.

Table 3. Empirical solvent parameters of the different solvent-water mixtures at $f_{1 / 2}$ mole fraction of water

\begin{tabular}{|c|c|c|c|c|c|}
\hline Solvent & $\mathrm{E}_{\mathrm{T}}(30)_{1 / 2} *$ & $Y_{1 / 2}^{\dagger}$ & $P_{1 / 2}^{\dagger}$ & $E_{1 / 2} \ddagger$ & $B_{1 / 2} \neq$ \\
\hline $\mathrm{MeOH}$ & $57.3 \pm 0.1$ & $0.9428 \pm 0.0005$ & $0.2109 \pm 0.0001$ & $18.4 \pm 0.1$ & $186.4 \pm 0.6$ \\
\hline $\mathrm{EtOH}$ & $55.3 \pm 0.1$ & $0.9429 \pm 0.0006$ & $0.2211 \pm 0.0002$ & $18.9 \pm 0.1$ & $178.1 \pm 0.8$ \\
\hline $\mathrm{ACN}$ & $56.1 \pm 0.3$ & $0.9517 \pm 0.0005$ & $0.2131 \pm 0.0002$ & $18.3 \pm 0.2$ & $156.8 \pm 0.1$ \\
\hline $\mathrm{ACE}$ & $55.8 \pm 0.3$ & $0.9461 \pm 0.0011$ & $0.2198 \pm 0.0004$ & $18.3 \pm 0.2$ & $168.2 \pm 0.7$ \\
\hline PYR & $54.7 \pm 0.2$ & $0.9478 \pm 0.0009$ & $0.2471 \pm 0.0029$ & $19.0 \pm 0.2$ & $197.1 \pm 3.2$ \\
\hline THF & $55.8 \pm 0.5$ & $0.9447 \pm 0.0019$ & $0.2253 \pm 0.0014$ & $19.2 \pm 0.2$ & $171.7 \pm 1.3$ \\
\hline \multirow{4}{*}{$\begin{array}{l}\text { Weighted mean value } \$ \\
\text { Relative SD\| }(\%) \\
\text { Sum of relative deviations II } \\
(\%)\end{array}$} & & & & & \\
\hline & $56.1 \pm 0.4$ & $0.9463 \pm 0.0014$ & $0.2133 \pm 0.0068$ & $18.7 \pm 0.2$ & $158.2 \pm 10.0$ \\
\hline & 1.6 & 0.36 & 7.8 & $2 . \overline{1}$ & 15.4 \\
\hline & 3.2 & 0.69 & 13.5 & 0.53 & 34.5 \\
\hline
\end{tabular}

*Taken from Reichardt and Dimroth (33), except for ACN and THF (see Materials and Methods).

$\dagger$ Calculated using $n_{1 / 2}$ and $\epsilon_{1 / 2}$ values from Table 2 .

$\$$ Calculated as additive functions of $f_{1 / 2}$, according to Palm (32).

$\S$ Calculated according to Szabo and Rayner (36), \pm SD.

$\|$ Relative standard deviation of the weighted mean values.

IISum of the relative deviations of the range of each mixture value from the range of the weighted mean value. 
This parameter reflects dipole-dipole (orientation) interactions. The specific solvation parameter electrophilicity (E) measures the Lewis acidity (electrophilic solvating power, hydrogen-bond donating ability).

Thus, the identical results obtained in this work by applying two quantitative approaches allow us to state that the association of Chl $a$ depends on the hydrogen-bonding and orientation interactions of the aqueous media irrespective of the kind of polar solvent. It is important to note that until now these parameters have been used to characterize only the properties of the medium, i.e. the interactions within the bulk system. With respect to $\mathrm{Chl} a$, these interactions can be considered indirect. Consequently, the conclusion is that the process of Chl $a$ self-assembly in aqueous medium is a solvent-structure-induced process. The Chl molecules are forced to come together and to associate when the hydrogenbonding and dipole-dipole interactions establish a certain degree of short- and long-range ordering in the bulk system qualitatively characterized by the values of parameters $E$ and $\mathrm{Y}$, respectively. The creation of a hydrogen-bond network in the system with or without the participation of the initial nonaqueous solvent in this network (38) is the driving force for Chl association in aqueous media. Thus, the correlation between the structure of the aqueous medium and $\mathrm{Chl}$ aggregation is established.

The solvents used arrange in the order $\mathrm{MeOH}<\mathrm{EtOH}<$ $\mathrm{ACN}<\mathrm{ACE}<\mathrm{PYR}<\mathrm{THF}$ with respect to the onset and $\mathrm{f}_{1 / 2}$ values. The findings that the parameter polarizability (P) and nucleophilicity (B) are different at the midpoint of the transition indicates that these two parameters are a specific, peculiar feature for the particular solvents that determine their different power in mixtures with water to the self-assembly of Chl $a$. Considering the structure of the bulk system, this finding also means that these two parameters determine the graded solvent effect $(\mathrm{MeOH}<\mathrm{EtOH}<\mathrm{ACN}$ $<\mathrm{ACE}<\mathrm{PYR}<\mathrm{THF}$ ) on the bulk structure. As is shown in the next section, the same two parameters are also responsible for the different types of Chl $a$ aggregate organization.

\section{Spectral characteristics of Chl $a$ solubility and aggregation}

In order to find a correlation between the solvent parameters and the type of $\mathrm{Chl}$ aggregates we compared the spectral characteristics at two important values of mole fractions of water established from Fig. 1. In all mixtures, at the onset and completion of transition, all $\mathrm{Chl}$ molecules are in monomeric and fully aggregated states, respectively. At these points, the interactions with and/or between solvent and water molecules are expected to be responsible for differences in the state of $\mathrm{Chl} a$.

Chl a in pure solvents and at the onset of transition. The comparison of spectra 1 and 2 in Fig. 2 for all samples shows that the increase in water content up to the onset values (see Table 4 for the respective values) has the most profound effect on the Soret band intensity $\left(\epsilon_{\mathrm{s}}\right)$. It is well established that the hydrogen bonding of solvent molecules at the carbonyl oxygen of the isocyclic ring changes the absorption spectra markedly (23). Renge and Avarmaa (23) have found an inverse linear correlation between $\epsilon_{\mathrm{s}}$ and the solvent pa-

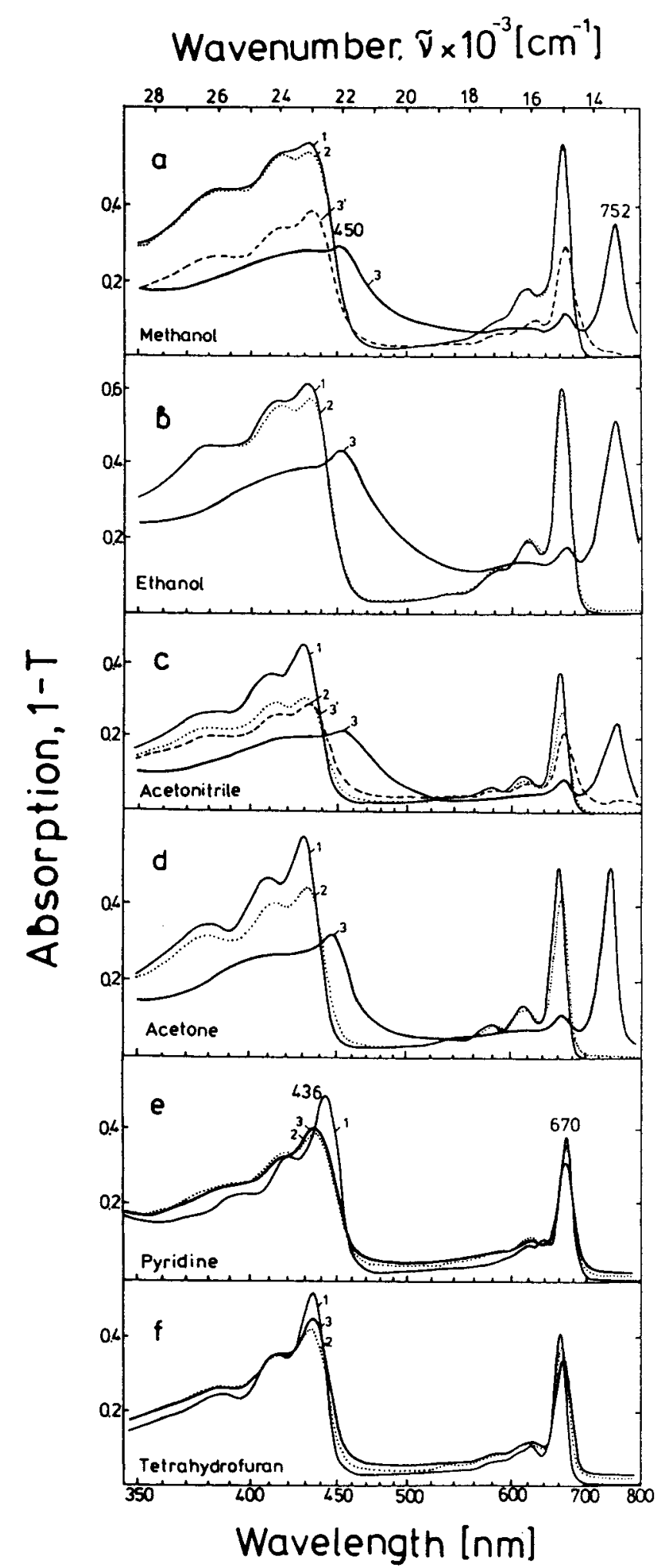

Figure 2. Absorption spectra of Chl $a(1-\mathrm{T}$, where $\mathrm{T}$ is the transmission) in the pure solvents (spectra $1(-))$ and in their mixtures with water at the onset (spectra $2(\cdots)$ ) and at the completion of the monomer $\rightarrow$ aggregate transition when equilibrium was reached (spectra 3 (- $(-)$ ). Spectra $3^{\prime}\left(-\right.$ - $^{-}$) in a and c are the spectra recorded just after the water admixing. The spectral transformations to the respective spectra 3 took $10-15 \mathrm{~h}$ and $8-10 \mathrm{~h}$, respectively. See Table 4 for the respective values of mole fractions of water. The $\mathrm{Chl}$ concentration was $2.7-5.7 \times 10^{-6} \mathrm{M}$. 


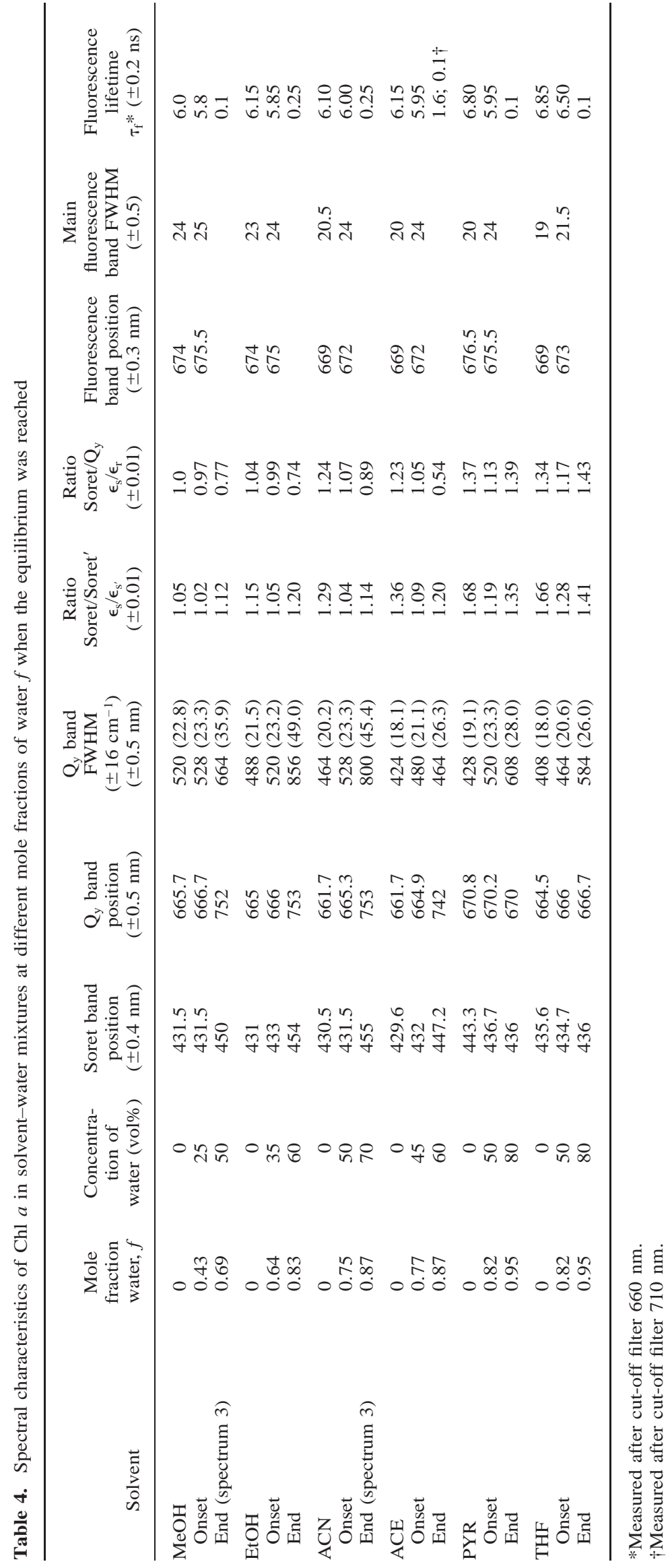


Table 5. Coordination number of the $\mathrm{Mg}$ atom and hydrogen bonding of $\mathrm{Chl} a$ short wavelength-absorbing forms

\begin{tabular}{|c|c|c|c|c|c|}
\hline $\begin{array}{l}\text { Solvent/water } \\
\text { mixtures }\end{array}$ & $\epsilon_{\mathrm{s}} / \epsilon_{\mathrm{s}^{\prime}}$ & $\begin{array}{l}\text { Soret } \\
\text { band } \\
\text { FWHM }\end{array}$ & $\begin{array}{l}\lambda(1 / 4 \text { Soret }) \\
(\mathrm{nm})\end{array}$ & $\frac{\epsilon\left(S_{2} \leftarrow S_{0}, \mathrm{~L}_{2}\right)}{\epsilon\left(S_{21} \leftarrow S_{0}, \mathrm{~L}_{1}\right)}$ & $\begin{array}{l}\text { Predominant type } \\
\text { of solvate }\end{array}$ \\
\hline $\begin{array}{l}\mathrm{MeOH} \\
\text { Onset } \\
\text { End (spectrum } 3^{\prime} \text { ) }\end{array}$ & $\begin{array}{l}1.05 \\
1.02 \\
1.16\end{array}$ & $\begin{array}{l}86 \\
88 \\
89\end{array}$ & $\begin{array}{l}452 \\
453 \\
456\end{array}$ & $\begin{array}{l}1.64 \\
1.61 \\
1.38\end{array}$ & $\begin{array}{l}\mathrm{L}_{2} \mathrm{H} \\
\mathrm{L}_{2} \mathrm{H} \\
\mathrm{L}_{1} \mathrm{H}\end{array}$ \\
\hline $\begin{array}{l}\text { EtOH } \\
\text { Onset } \\
\text { End* }\end{array}$ & $\begin{array}{l}1.15 \\
1.05 \\
1.12\end{array}$ & $\begin{array}{l}77 \\
86 \\
93\end{array}$ & $\begin{array}{l}449 \\
451 \\
457\end{array}$ & $\begin{array}{l}1.36 \\
1.33 \\
1.37\end{array}$ & $\begin{array}{l}\mathrm{L}_{1} \mathrm{H} \\
\mathrm{L}_{1} \mathrm{H} \\
\mathrm{L}_{1} \mathrm{H}\end{array}$ \\
\hline $\begin{array}{l}\text { ACN } \\
\text { Onset } \\
\text { End (spectrum 3') }\end{array}$ & $\begin{array}{l}1.29 \\
1.04 \\
1.11\end{array}$ & $\begin{array}{l}64 \\
85 \\
84\end{array}$ & $\begin{array}{l}444 \\
450 \\
453\end{array}$ & $\begin{array}{l}1.00 \\
1.12 \\
1.17\end{array}$ & $\begin{array}{l}\mathrm{L}_{1} \\
\mathrm{~L}_{1} \mathrm{H} \\
\mathrm{L}_{1} \mathrm{H}\end{array}$ \\
\hline $\begin{array}{l}\text { ACE } \\
\text { Onset }\end{array}$ & $\begin{array}{l}1.36 \\
1.09\end{array}$ & $\begin{array}{l}44 \\
78\end{array}$ & $\begin{array}{l}442 \\
447\end{array}$ & $\begin{array}{l}1.00 \\
1.14\end{array}$ & $\begin{array}{l}\mathrm{L}_{1} \\
\mathrm{~L}_{1} \mathrm{H}\end{array}$ \\
\hline $\begin{array}{l}\text { PYR } \\
\text { Onset } \\
\text { End (spectrum 3) }\end{array}$ & $\begin{array}{l}1.68 \\
1.19 \\
1.35\end{array}$ & $\begin{array}{l}38 \\
84 \\
72\end{array}$ & $\begin{array}{l}455 \\
457 \\
455\end{array}$ & $\begin{array}{l}2.23 \\
1.61 \\
1.68\end{array}$ & $\begin{array}{l}\mathrm{L}_{2} \\
\mathrm{~L}_{2} \text { and } \mathrm{L}_{1} \mathrm{H} \text { (weak) } \\
\mathrm{L}_{2}\end{array}$ \\
\hline $\begin{array}{l}\text { THF } \\
\text { Onset } \\
\text { End (spectrum 3) }\end{array}$ & $\begin{array}{l}1.66 \\
1.28 \\
1.41\end{array}$ & $\begin{array}{l}39 \\
70 \\
47\end{array}$ & $\begin{array}{l}450 \\
450 \\
451\end{array}$ & $\begin{array}{l}1.90 \\
1.90 \\
1.78\end{array}$ & $\begin{array}{l}\mathrm{L}_{2} \\
\mathrm{~L}_{2} \\
\mathrm{~L}_{2}\end{array}$ \\
\hline
\end{tabular}

*Observed at the instant of 50\% water admixing and concentration of Chl $a 3 \times 10^{-5} \mathrm{M}$.

rameter $\mathrm{E}$, while $\epsilon_{\mathrm{s}^{\prime}}$ changes little in different solvents. Based on this, the authors concluded that the ratio $\epsilon_{\mathrm{s}} / \epsilon_{\mathrm{s}^{\prime}}$ can be considered as a measure of the strength of hydrogen-bonding interactions of Chl $a$ with electrophilic solvent molecules. Because the added electrophilic molecules are the water molecules, the values of $\epsilon_{\mathrm{s}} / \epsilon_{\mathrm{s}^{\prime}}$ (Table 4) reflect the degree of Chl $a$ hydration. This ratio is very similar in $\mathrm{MeOH}$, EtOH, ACN and ACE (1.02-1.09), while in PYR and THF it is considerably higher (1.19-1.28). The degree of hydration of monomeric Chl $a$ in different solvent-water mixtures decreases in the order $\mathrm{MeOH}>\mathrm{EtOH}=\mathrm{ACN}>\mathrm{ACE}>\mathrm{PYR}$ $>$ THF.

The decrease of $\epsilon_{\mathrm{s}^{\prime}} / \epsilon_{\mathrm{s}^{\prime}}$ accompanied with the concomitant increase of Soret band FWHM (full width at half maximum) is established by Renge and Avarmaa (23) as a marker for the existence of hydrogen bonding mainly to the Chl $a$ keto carbonyl group (see the original paper for the respective spectral values and solvent parameters). Table 5 presents the assignment of the hydrogen bonding based on these spectral features.

The assignment of a coordination number 5 or 6 to the $\mathrm{Mg}$ atom, i.e. $\mathrm{L}_{1}$ or $\mathrm{L}_{2}$ types of specific solvates of Chl a, was based on the other two semiquantitative indices of the absorption spectra introduced by Renge and Bitova (24). The relative content of $\mathrm{L}_{2}$ and $\mathrm{L}_{1}$ solvates can be determined from the ratio $\epsilon\left(S_{2} \leftarrow S_{0}, L_{2}\right) / \epsilon\left(S_{21} \leftarrow S_{0}, L_{1}\right)$. The value of $\epsilon\left(S_{2} \leftarrow S_{0}, L_{2}\right)$ is taken at the wavelength of the minimum between the $\mathrm{S}_{1} \leftarrow \mathrm{S}_{0}\left(\mathrm{Q}_{\mathrm{y}}\right)$ and $\mathrm{S}_{11} \leftarrow \mathrm{S}_{0}$ bands (usually at $\sim 610 \mathrm{~nm})$; the value of $\epsilon\left(S_{21} \leftarrow S_{0}, L_{1}\right)$ is taken at the wavelength where there is a maximum of the $S_{21} \leftarrow S_{0}$ band of the Chl $a \cdot \mathrm{L}_{1}$ complex (usually at $\sim 580 \mathrm{~nm}$ ). It is important to note that recently Umetsu et al. (39) have confirmed the sensitivity of these spectral regions to the coordination state of Chl $a$. An additional indication for the coexistence of $\mathrm{L}_{2}$ and $\mathrm{L}_{1}$ solvates is the wavelength (in red direction) at which the Soret band intensity is a quarter of the maximum $(\lambda[1 / 4$
Soret]). Table 5 presents the coordination number of $\mathrm{Mg}$ as determined with these indices. It is important to note that in pure solvents the same assignment of the coordination number of $\mathrm{Mg}$ and the hydrogen bonding of Chl $a$ is derived when the resonance Raman (RR) markers are used $(28,29)$. In this sense, the assignment of hydrogen-bonding and coordination interactions is well founded by the RR data.

In all mixtures at the onset of transition, with exception of THF (Table 4), the changes in absorption characteristics are accompanied with a $20 \%$ increase in the fluorescence band FWHM and the reduction of fluorescence lifetime $\tau_{\mathrm{f}}$ to the values close to those in $\mathrm{MeOH}$ and $\mathrm{EtOH}$. It was found that the existence of hydrogen bonding with solvent remarkably $(30-40 \%)$ increases the FWHM of the main fluorescence band of Chl $b$ at $5 \mathrm{~K}$ (40). The effect is the same for Chl $a$ at room temperature (35). A 20-25\% increase in FWHM was established by comparing the fluorescence spectra of Chl $a$ in polar solvents with and without hydrogenbond donating ability. Such differences cannot be explained solely by the effect of the dielectric constant. The same is seen with the comparison of fluorescence halfwidth in pure solvents (Table 4). The fluorescence lifetime is also solvent dependent (41), being lowest in alcohols and highest in aprotic polar solvents. In the case of nondegassed polar solvents, practically no difference exists between $\mathrm{L}_{1}$ and $\mathrm{L}_{1(2)} \mathrm{H}$ solvates. Thus, these fluorescence parameters confirm the assignments presented in Table 5 .

To sum up, at the onset of the transition, when the Chl is still in monomeric form, PYR and THF behave differently compared to the other four solvents in mixtures with water, not only by the lower degree of hydration, expressed by the higher values of $\epsilon_{\mathrm{s}} / \epsilon_{\mathrm{s}^{\prime}}$, but also in their ability to stabilize the predominantly six-coordinated state of the $\mathrm{Mg}$ atom and by the absence of a strong hydrogen-bonded water molecule. This finding can be explained by the higher values of parameters $\mathrm{P}$ and $\mathrm{B}$ for PYR and THF. It is important to note that 
the hydration of Chl $a$ decreases in the same order just as the stabilization of hexacoordinated $\mathrm{Mg}$ increases in different solvent-water mixtures. Based on this, it can be concluded that maintaining $\mathrm{Chl} a$ in monomeric state is a balance between the hydration and preferential solvation by strongly nucleophilic solvents.

Chl a aggregates in different mixtures before and when equilibrium was reached. The spectral transformations in different solvents took different times after the addition of water. In EtOH, ACE, PYR and THF, the aggregates presented as spectra 3 in Fig. 2 were formed just after the water admixing. No additional spectral transformations were observed during prolonged monitoring (2 days). In $\mathrm{MeOH}$ and ACN after water admixing, the short-wavelength-absorbing aggregate appears (spectra 3', Fig. 2) with characteristic red band tailing toward the longer wavelength region and the appearance of a small peak in that region. Its direct conversion to those presented with spectra 3 in Fig. 2 took 10-15 and $8-10 \mathrm{~h}$, respectively. No additional transformations of spectra 3 were observed after prolonged standing (2 days). The state of aggregation in $\mathrm{MeOH}$ and $\mathrm{EtOH}$ was examined during a 1 week period. No changes in the shape of the spectra or in the absorption maxima were detected.

Comparison of the spectra at the completion of transition (spectra 3 in Fig. 2, Table 4) demonstrates the profound difference in the types of aggregates formed in $\mathrm{MeOH}-$, EtOH-, ACN-, and ACE-water mixtures, on one side, and in PYR and THF, on the other side. Thus, the solvents can be divided into two groups based on their disparate effect on the type of $\mathrm{Chl}$ aggregate formation. The first group $(\mathrm{MeOH}, \mathrm{EtOH}, \mathrm{ACE}, \mathrm{ACN})$ in mixture with water gives rise to a strongly red-shifted Chl aggregate with Soret $\lambda_{\max }$ at 445-455 $\mathrm{nm}$ and $\mathrm{Q}_{\mathrm{y}} \lambda_{\max }$ at 742-753 nm (C750). The shape of the spectra in $\mathrm{MeOH}-$, EtOH-, ACN-, and ACE-water mixtures (Fig. 2, spectra 3 and Table 4) is very similar. This spectral form is usually ascribed to the polymeric species of dihydrated $\mathrm{Chl} a\left(\mathrm{Chl} a \cdot 2 \mathrm{H}_{2} \mathrm{O}\right)_{\mathrm{n}}(8)$. The single Chl $a$ molecule is hydrogen bonded to a water molecule and the second water molecule is the fifth ligand to the $\mathrm{Mg}$ of Chl $a$. Recently, Oba et al. (42) confirmed this assignment for the polar solvent-water mixture (aqueous 2-propanol) by using RR spectroscopy. Thus, the main conclusion from this comparison is that in the group I solvents, the water molecules succeed to replace the initial solvent molecules from the first solvation shell of Chl $a$ giving rise to the polymeric aggregates of the type $\left(\mathrm{Chl} a \cdot 2 \mathrm{H}_{2} \mathrm{O}\right)_{\mathrm{n}}$, while in group II (PYR and THF) water is not able to do this. Alfano et al. (43) have shown that the fluorescence lifetime of such aggregates can be used for estimation of their aggregation number. It is equal to the $\tau_{f}$ of the monomer divided by the $\tau_{f}$ of the aggregate. The time and intensity resolution of our apparatus for fluorescence lifetime measurements was insufficient for precise measurements on practically nonfluorescent probes. Nevertheless, the lifetimes presented in Table 4 can be used for rough estimation of the aggregate number. For ACEwater mixtures, the average fluorescence lifetime of the whole emission spectrum (using a $660 \mathrm{~nm}$ cut-off filter) was $1.6 \mathrm{~ns}$, while in the long wavelength part of the spectrum (using a $710 \mathrm{~nm}$ cut-off filter) it was about $0.1 \mathrm{~ns}$. This value yields an aggregate size of $\mathrm{n}>60$ molecules. For $\mathrm{MeOH}$, EtOH and ACN, the signal was so small that it did not allow us to measure in the long wavelength part of the emission spectrum. The lifetimes registered for the whole emission spectrum (using a $660 \mathrm{~nm}$ cut-off filter) for these mixtures (Table 4) suggest a larger size of aggregates ( $\mathrm{>}>100)$ compared with those in the ACE-water mixtures. These lifetime differences could be used to explain the difference in the absorption maximum, $742 \mathrm{~nm}$ for ACE and $752 \mathrm{~nm}$ for the other three solvents, with the different aggregation number. Note that the same difference in absorption spectra exists between ethyl- and methyl-chlorophyllide $a$ microcrystals (44); nevertheless, both chlorophyllides occur as crystalline dihydrates.

In contrast, the spectra of Chl $a$ with the group II solventwater mixtures (Fig. 2, spectra 3e, 3f) and those formed at the initial stage of the aggregation with the group I solvents (Fig. 2, spectra $3^{\prime}$ ) as a whole differ slightly from the monomeric ones. The main differences in comparing the monomers in pure solvents are an increase in the ratio Soret/ $\mathrm{Q}_{\mathrm{y}}$, with a concomitant decrease of the intensity of the $\mathrm{Q}_{\mathrm{y}}$ band, an increase of light scattering and, of course, absence of fluorescence and extremely short fluorescence lifetimes. Compared with the form at the onset of the transition, the $\epsilon_{\mathrm{s}} / \epsilon_{\mathrm{s}^{\prime}}$ ratio increases (clear indication for the decreased hydration of Chl), the Soret band halfwidth decreases and $\mathrm{Q}_{\mathrm{y}}$ intensity decreases $\left(\epsilon_{\mathrm{s}^{\prime}} / \epsilon_{\mathrm{r}}\right.$ ratio increases, Tables 4 and 5$)$. The spectra $3^{\prime}$ and spectra 3 of PYR and THF (Fig. 2) are identical to those of the typical colloidal aggregate of Chl $a$ observed in various polar solvent-water mixtures $(9,10,13,16,45)$. The exact location of the red absorption band in the $670-675 \mathrm{~nm}$ region and the ratio $\epsilon_{\mathrm{s}} / \epsilon_{\mathrm{s}^{\prime}}$ depends on the conditions of mixing and the concentration of Chl. This dependence is also seen in the results for EtOH-water done at higher concentrations of Chl $a$ and at different mixing conditions (Table 6). The fluorescence lifetimes of the transient colloidal aggregate C670 and of the C750 aggregate in $\mathrm{MeOH}$ and $\mathrm{ACN}$ are equal.

Based on the monomer-like absorption spectra of the C670 aggregate, it was possible to determine the coordination number of the $\mathrm{Mg}$ and the hydrogen bonding in the same way as described for monomeric Chl $a$. Table 5 presents these data and allows a comparison between the different observed absorption forms, both stable and transient. Thus, in contrast to the stable C750 aggregates and its precursor C670, this form in PYR and THF is built from predominantly six-coordinated Chl $a$ by two solvent (not water) molecules, and H-bonding interactions do not play a decisive role in its stability. The absorption spectra of the transient aggregate C670 (spectra 3', Fig. 2) is identical to that in aqueous dimethylsulfoxide (DMSO) (16). Koyama et al. (29) determined that Chl $a$ in aqueous DMSO is five-coordinated and hydrogen bonded by using RR spectroscopy. In this sense, the assignment made here for the transient colloidal C670 aggregate is substantiated by RR data.

Comparison between the colloidal aggregates C670. The C670 aggregate in PYR and THF-water, $\left(\mathrm{Chl} a \cdot \mathrm{L}_{2}\right)_{\mathrm{n}}$, and the transient $\mathrm{C} 670$ aggregate in $\mathrm{MeOH}$ and $\mathrm{ACN}$-water, (Chl $\left.a \cdot \mathrm{L}_{1} \cdot \mathrm{H}_{2} \mathrm{O}\right)_{\mathrm{n}}$, also differ in their spectral parameter $\epsilon_{\mathrm{s}^{\prime}} / \epsilon_{\mathrm{r}}$ and in the width of the red band ( $c f$. Fig. 2, spectra 3 and $3^{\prime}$ ). Table 6 presents these data as well as a comparison with other systems. In both aggregates the absorption maximum is located at $670 \mathrm{~nm}$, an indication that the $\pi$-electrons of 
the adjacent molecules have no overlap. But as these aggregates differ in the number of the $\mathrm{Mg}$ axial ligands and the six-coordination can suppress the closeness of the macrocycles compared to the five-coordinated $\mathrm{Mg}$, it is intuitively obvious that they can differ in their molecular packing density in the region of the chlorin macrocycles. In order to test this assumption, we compared the absorption parameters of Chl $a$ monolayers at different pressures (46) that are also included in Table 6. It is clearly evident from the values of the absorption parameters corresponding to the area per molecule of $98 \AA^{2}$ and $37 \AA^{2}$ that the increase in the spectral parameter $\epsilon_{\mathrm{s}^{\prime}} / \epsilon_{\mathrm{r}}$ and the width of the red band reflect the increased packing density. Thus, it can be concluded that aggregates of the type $\left(\mathrm{Chl} a \cdot \mathrm{L}_{2}\right)_{\mathrm{n}}$ have a higher area per $\mathrm{Chl}$ molecule exposed to the water subphase compared with the aggregates of the type $\left(\mathrm{Chl} a \cdot \mathrm{L}_{1} \cdot \mathrm{H}_{2} \mathrm{O}\right)_{\mathrm{n}}$. On the other hand, it is known that the $\mathrm{C} 750$ form, $\left(\mathrm{Chl} a \cdot 2 \mathrm{H}_{2} \mathrm{O}\right)_{\mathrm{n}}$, which is peculiar with its regular stacking of the $\mathrm{Chl}$ macrocycles and the shortest distance between them, has the smallest area per Chl molecule of $17 \AA^{2}$ (47).

If we compare the solvation parameters of PYR and THF with those of the other four solvents and water (Table 1), it is clear that they differ with respect to their nucleophilicity (B) and polarizability (P) parameters. Thus, it can be concluded that these parameters are important for the disparate effect the two groups of solvents have on the solubility and aggregation of Chl $a$ in aqueous media.

\section{How the environment modulates the type of $\mathrm{Chl}$ organization}

The nonspecific polarizability parameter $(\mathrm{P})$ is a function of the index of refraction of the medium, $P=\left(n^{2}-1\right) /\left(n^{2}+\right.$ $2)$, and reflects dipole-induced dipole interactions, according to classical dielectric theory (32). The larger the polarizability of a solvent, the greater its ability to bind to polarizable and weakly hydrophobic sites. For the case of Chl $a$, Seely and Jensen (26) have shown that aromatic molecules such as PYR and THF produce the greatest solvation effects on Chl that may result from some $\pi$ complexation with the porphyrin ring. On the other hand, there is a well-established correlation between the polarizability of various low-molecular weight substances and their water structure-breaking activity $(38,48)$. Obviously, both properties of highly polarizable solvents (PYR and THF) — a propensity for enhanced solvation of Chl $a$ and the disruption of water structurewould be complimented in retaining the $\mathrm{Chl}$ in a monomeric state at higher water concentrations, when compared to solvents of group I, as well as preventing higher aggregation utilizing water molecules.

The nucleophilicity parameter (B) measures the Lewis basicity (nucleophilic solvating power, electron pair donating ability) of the solvent. It is similar to the well-known donor number parameter (21), and similarly, it is proportional to the strength of electron donor-acceptor interactions. As the $\mathrm{Mg}^{2+}$ of Chl $a$ is the strongest electron-accepting center, the value of $\mathrm{B}$ is proportional to the strength of solvent-Mg coordination interaction. Thus, the higher polarizability and coordination abilities of PYR and THF, exerted via the preferential solvation and strong coordination interaction, maintain the hexacoordinated state of $\mathrm{Mg}$ and in this way prevent 
Table 7. Uneven solvent distribution at the Chl $a$-water interface and in the bulk system for Chl $a$ aggregates formed in the two groups of solvent-water mixtures

\begin{tabular}{llcccc}
\hline Solvent & \multicolumn{1}{c}{$\begin{array}{c}\text { Type of } \\
\text { aggregate }\end{array}$} & $\begin{array}{c}\text { Solvent/water } \\
\text { mole ratio at } \\
\text { the interface }\end{array}$ & $\begin{array}{c}\text { Mole fractions } \\
\text { of water } \\
\text { in bulk }\end{array}$ & $\begin{array}{c}\text { Solvent/water } \\
\text { mole ratio in } \\
\text { bulk system }\end{array}$ & $\begin{array}{c}\text { Solvent distribution } \\
\text { at the interface } \\
\text { compared to the bulk }\end{array}$ \\
\hline $\mathrm{MeOH}$ & $\mathrm{C} 750\left(\mathrm{Chl} \cdot 2 \mathrm{H}_{2} \mathrm{O}\right)_{\mathrm{n}>>2}$ & $0: 2$ & 0.69 & $1: 2.3$ & Depletion \\
EtOH & $\mathrm{C} 750\left(\mathrm{Chl} \cdot 2 \mathrm{H}_{2} \mathrm{O}\right)_{\mathrm{n}>>2}$ & $0: 2$ & 0.83 & $1: 4.88$ & Depletion \\
$\mathrm{ACN}$ & $\mathrm{C} 750\left(\mathrm{Chl} \cdot 2 \mathrm{H}_{2} \mathrm{O}\right)_{\mathrm{n}>>2}$ & $0: 2$ & 0.87 & $1: 6.7$ & Depletion \\
$\mathrm{ACE}$ & $\mathrm{C} 750\left(\mathrm{Chl} \cdot 2 \mathrm{H}_{2} \mathrm{O}\right)_{\mathrm{n}>>2}$ & $0: 2$ & 0.87 & $1: 6.7$ & Depletion \\
$\mathrm{PYR}$ & $\mathrm{C} 670(\mathrm{Chl} \cdot 2 \mathrm{PYR})_{\mathrm{n}>>2}$ & $2: 0$ & 0.95 & $1: 19$ & Enrichment \\
THF & $\mathrm{C} 670(\mathrm{Chl} \cdot 2 \mathrm{THF})_{\mathrm{n}>>2}$ & $2: 0$ & 0.95 & $1: 19$ & Enrichment \\
\hline
\end{tabular}

the higher hydration of monomeric Chl $a$ at higher water content. The strong solvation of the Chl macrocycles by these monofunctional solvents does not allow strong macrocycle-macrocycle interactions mediated by water and the formation of higher aggregates $\mathrm{C} 750$ by using the water molecules. It is clear that the looseness of the molecular packing at the macrocycle region requires the involvement of phytolphytol interactions for the relative stability of these aggregates in aqueous media.

\section{Mechanism of Chl $a$ dissolution and aggregation in aqueous media}

Three main findings of this work: (1) the correlation between the structure of the medium and the aggregation of Chl $a$; (2) the graded response of the solvents with respect to the water content at the onset and the midpoint of Chl $a$ monomer $\rightarrow$ aggregate transformation; (3) the differentiation of the solvents into two groups, based on the disparate effects that they exert on the $\mathrm{Chl} a$ aggregate organization, are a consistent advantage that permits the elucidation of the mechanism for Chl dissolution and aggregation in various aqueous media. The established ordering of solvents$\mathrm{MeOH}<\mathrm{EtOH}<\mathrm{ACN}<\mathrm{ACE}<\mathrm{PYR}<\mathrm{THF}$-yields a typical lyotropic (Hofmeister) series (49). Much smaller amounts of THF and PYR are needed to disrupt medium structure (i.e. to keep the $\mathrm{Chl}$ monomer from associating with others) compared to the solvents on the left side of the order $(\mathrm{MeOH}, \mathrm{EtOH})$. The ability of many substances of low-molecular weight (salts, solvents, amino acids, etc.) to exhibit lyotropic effects on the solubility, stability and functional activity of biological macromolecules and biomolecular assemblies is well known $(48,49)$. A large number of experimental studies show that the properties of the interface between aqueous and nonaqueous phases can be markedly affected via indirect interactions with added substances (49). These substances stabilize or destabilize the structure of bulk water (liquid) and thus influence the properties of interfacial water (the Hofmeister effect). The particular solvents in such series exert disparate effects on the behavior of biological macromolecules or biomolecular assemblies, depending on their position in the Hofmeister series, i.e. depending on their effect on bulk structure (48-50). The solvents on the left side of the Hofmeister series are termed kosmotropes (structure makers) and usually stabilize native protein conformation. In contrast, those on the right side of the series, termed chaotropes (structure breakers), destabilize native protein conformation. The tendency of Hofmeister solutes to distribute unevenly between bulk system and interfaces is a well-known experimental fact $(48,49)$. It is also generally recognized that kosmotropes favor the stability of conformations with reduced surface area, while chaotropes favor those with increased surface area. For the case of modulation of lipid-phase behavior by kosmotropes and chaotropes these experimental observations have recently been theoretically substantiated (50). The derived general thermodynamic equation provides a clear description in physical quantities of the disparate effects of the different substances on the lipid-phase behavior. According to that equation, kosmotropes and chaotropes have opposite effects on the lipid-phase behavior due to their uneven distribution between interfacial (bound) and bulk (free) water. Kosmotropes tend to be excluded from the interface, while chaotropes tend to accumulate at the interface. Kosmotropes favor the $\mathrm{L}_{\beta}$ (gel) and the inverted hexagonal $\mathrm{H}_{\mathrm{II}}$ phases at the expense of the $\mathrm{L}_{\alpha}$ (liquid crystalline) phase, as the former phases have reduced area per lipid molecule exposed to water. To the contrary, chaotropes tend to expand the lipid interface area and favor the $\mathrm{L}_{\alpha}$ phase, as that phase has the largest area per lipid molecule.

It is evident from Table 7 that just as displayed in lipidphase behavior, the two groups of solvents exert their disparate effects on $\mathrm{Chl}$ aggregate organization. The solvents from group I (MeOH, EtOH, ACE and ACN) act as kosmotropic substances. They stabilize the structure of bulk liquid (their position in the series) and tend to be excluded from the interfacial Chl-water regions (Table 7). In turn, this brings about a tendency to reduce the energetically unfavorable area of Chl-water contact. The surface area per Chl molecule is strongly reduced by the formation of the twowater hydrogen-bonding network that keeps the Chl macrocyles close to each other. These solvents favor the C750 aggregates at the expense of $\mathrm{C} 670$ as the former aggregate has the smallest surface area per Chl molecule at the interface between aqueous and nonaqueous phases. By the same argument, the solvents from group II (PYR and THF) act as chaotropes. They tend to disrupt the bulk structure (their position in the series), accumulate at the Chl interface and directly interact with $\mathrm{Chl}$ electrophilic interfacial group $\mathrm{Mg}^{2+}$ (Table 7). They support the C670 aggregate, as it has the largest area per $\mathrm{Chl}$ molecule exposed at the interface. Thus, based on these data concerning the disparate effect of solvents on Chl aggregates, we have shown that the mechanism for Chl self-assembly in aqueous media can be considered a manifestation of the Hofmeister effect, as displayed 
in lipid-phase behavior (50). It relates on the solvent ability to modify the bulk structure and to distribute unevenly between the Chl-water interface and bulk liquid.

The proposed mechanism for modulation of Chl aggregates by kosmotropic and chaotropic cosolvents can explain the formation of special Chl aggregates absorbing in the 685-695 $\mathrm{nm}$ region that are formed only in certain polar solvent-water mixtures $(9,16,17)$. A characteristic feature of these aggregates is that water does not participate as a ligand or in hydrogen bonding to the Chl molecule. Their stabilization can be explained by the chaotropic manner of action of either a bifunctional solvent such as dioxane or dimers of DMSO and THF, just as the chaotropes are able to induce and stabilize missing phases in the phase sequence of certain lipid-water systems (50). The proposed mechanism can also explain the observed suppressing effect of urea and imidazole on the formation of C690 aggregates in formamidewater systems (11), due to their strong chaotropic nature. This mechanism also explains the established inverse correlation (5) between the refractive index and the optimal concentration of the organic solvents effective in producing the $740 \mathrm{~nm}$-absorbing $\mathrm{Chl}$ aggregates in chloroplast fragments.

\section{How to correlate the present results on $\mathrm{Chl}$ aggregation in aqueous media with the Chl-Chl interactions observed in photosynthetic complexes}

The main problem of many model studies is how to relate the observed results on $\mathrm{Chl}$ aggregation to the spectra-structure-function relationship with native systems. Usually, the stable dimers formed in particular aqueous solvents are suitable models for the reaction centers Chl $a$. It must be noted that the C750 aggregates and C670 in PYR and THF-water mixtures are not physiologically important species. They are only observed during the treatment of chloroplast fragments (5) or chlorosomes (3). As is evident from the comparison of absorption characteristics of $\mathrm{Chl} a$-enriched preparations and Chl $b$-less mutants with those of the C670 aggregates studied here (Table 6), only the precursor of the C750 aggregates, i.e. the transient $\mathrm{C} 670$ aggregate of the type (Chl $\left.a \cdot \mathrm{L}_{1} \cdot \mathrm{H}_{2} \mathrm{O}\right)_{\mathrm{n}}$ can have a certain physiological importance. Its absorption characteristics $\epsilon_{\mathrm{s}} / \epsilon_{\mathrm{r}}, \epsilon_{\mathrm{s}} / \epsilon_{\mathrm{s}^{\prime}}$, and $\epsilon_{\mathrm{s}^{\prime}} / \epsilon_{\mathrm{r}}$, FWHM, the very low fluorescence quantum yield and fluorescence lifetime are very similar if not identical to those of the Chl $a$ in vivo ( $c f$. Table 6 and Holzwarth (55) for the fluorescence lifetimes of antenna Chl complexes). To the best of our knowledge, the close similarity in the absorption characteristics of $\epsilon_{\mathrm{s}} / \epsilon_{\mathrm{r}}, \epsilon_{\mathrm{s}} / \epsilon_{\mathrm{s}^{\prime}}$, and $\epsilon_{\mathrm{s}^{\prime}} / \epsilon_{\mathrm{r}}$ between the Chl $a$ aggregates in aqueous media and Chl $a$ in native systems is reported for the first time. In 1965 Clayton (56) suggested that the amorphous monolayers and colloidal $\mathrm{Chl}$ might be good models for Chl $a$ aggregates in vivo, based on the close similarity in the positions of absorption maxima. In addition to his hypothesis, we point out that only a metastable Chl organization, i.e. Chl aggregate organization at the boundary of its stability, could explain the finding that antenna $\mathrm{Chl} a$ has a structural role in stabilizing the functional conformation of P700-chlorophyll-protein complexes (57), as well as the appearance of $740 \mathrm{~nm} \mathrm{Chl} \mathrm{forms} \mathrm{during} \mathrm{the} \mathrm{treatment}$ of chloroplast fragments with kosmotropic solvents (5).
In the present work, the main focus was on finding a correlation between the structure and properties of the medium and the process of $\mathrm{Chl}$ aggregation and, in this way, shed light on the possible mechanism for $\mathrm{Chl}$ aggregation in aqueous media. In this regard, another aspect of the relevance to in vivo systems is reported here. In the present work, it is found that $\mathrm{Chl}$ association and stabilization of different aggregated forms are governed by the same mechanism as those that modulate the organization and stability of the other two components of photosynthetic membranes: lipids and proteins. In this sense, the results presented here are mainly of importance to indirect studies of pigment organization in vivo. The strength of $\mathrm{Chl}-\mathrm{Chl}(\mathrm{Bchl}-\mathrm{Bchl})$ interactions in the photosynthetic complexes can be modulated subtly by varying the nature of additives to the system. These interactions can be influenced by $\mathrm{pH}$, salt concentration, buffer and different stress conditions (high and low temperature, dehydration, etc.). Thus, the connection between these model systems and the native ones is the common mechanism modulating their stability.

The power of this common mechanism can be further exemplified by the explanation of the experimental fact that the glycolipid monolayer is not destroyed during the 1-hexanol treatment of the native chlorosomes (58), while the Bchl $c, d$ aggregates absorbing at $740-750 \mathrm{~nm}$ are converted to $670 \mathrm{~nm}$-absorbing aggregates (4). It is known that at low concentrations, all solvents behave as water structure breakers: they interact with water and disrupt the normal type of long-range order (38). Thus, the conversion of 740-750 nmabsorbing Bchl $c, d$ species can be explained by the enrichment of Bchl interfacial regions with 1-hexanol that stabilizes the aggregates absorbing at $670 \mathrm{~nm}$, very similarly to those considered here. On the other hand, the inversion point in the Hofmeister series for glycolipid dispersions in water is positioned at the chaotropic end of the Hofmeister series (50). The sign inversion point in these series depends on the effect of the particular biomolecule on the structure of water $(50,59)$. Compared with other lipid classes and Chl $a$, the effect of chaotropes on the stability of glycolipid phases is the smallest one. This explains why the addition of 1-hexanol does not affect the glycolipid monolayer structure of chlorosomes.

Acknowledgements - The author thanks Dr. D. Kafalieva-Nikolov for the gift of Chl $a$ and for advice. The continuous discussions during the preparation of this manuscript and its critical reading by Dr. R. Koynova are greatly acknowledged. The author thanks Dr. D. Leupold for the critical reading of the first manuscript and for advice. The author is grateful to Prof. B. Tenchov for support and advice. The discussions with Dr. T. Oba, Dr. I. Renge, Dr. K. Teuchner and V. Kolev are also acknowledged. The author thanks the reviewer for the suggestion concerning the possible role of polarizability and hexacoordination. This work was financially supported by the Bulgarian Academy of Sceinces.

\section{REFERENCES}

1. Olson, J. M. (1998) Chlorophyll organization and function in green photosynthetic bacteria. Photochem. Photobiol. 67, 6175 .

2. Paulsen, H. (1995) Chlorophyll $a / b$-binding proteins. Photochem. Photobiol. 62, 367-382.

3. Brune, D. C., T. Nozawa and R. E. Blankenship (1987) Antenna organization in green photosynthetic bacteria. 1. Oligomeric bacteriochlorophyll $c$ as a model for the $740 \mathrm{~nm}$ absorbing bac- 
teriochlorophyll $c$ in Chloroflexus aurantiacus chlorosomes. Biochemistry 26, 8644-8652.

4. Zhu, Y., S. Lin, B. L. Ramakrishna, P. I. van Noort and R. E. Blankenship (1996) Self quenching of chlorosome chlorophylls in water and hexanol-saturated water. Photosynth. Res. 47, 207218.

5. Lippincott, J. A., J. Aghion, E. Porcile and W. F. Bertsch (1962) The preparation and characterization of chloroplast fragments having an absorbancy maximum at $7400 \AA$. Arch. Biochim. Biophys. 98, 17-27

6. Dijkmans, H. and J. Aghion (1974) Conditions de formation d'agrégats de chlorophylle $a$ dans des solvants polaires aqueux: polarité du milieu. Plant \& Cell Physiol. 15, 739-745.

7. Scherz, A., V. Rosenbach-Belkin and J. R. E. Fisher (1991) Chlorophyll aggregation in aqueous solutions. In Chlorophylls (Edited by H. Scheer), pp. 237-268. CRC Press, Boca Raton, FL.

8. Katz, J. J., M. K. Bowman, T. J. Michalski and D. L. Worcester (1991) Chlorophyll aggregation: chlorophyll/water micelles as models for in vivo long-wavelength chlorophyll. In Chlorophylls (Edited by H. Scheer), pp. 211-235. CRC Press, Boca Raton, FL.

9. Love, B. B. (1962) Absorption spectra of chlorophyll $a$ in aqueous carbitol solutions. Biochim. Biophys. Acta 64, 318-323.

10. Love, B. B. and T. T. Bannister (1963) Studies of colloidal chlorophyll in aqueous dioxane. Biophys. J. 3, 99-113.

11. Quilman, K. P. (1968) Aggregation of chlorophylls in aqueousformamide solutions. Arch. Biochim. Biophys. 127, 31-36.

12. Journeaux, R., A. Hochapfel and R. Viovy (1969) Existence et nature des formes agrégées de la chlorophylle $a$ dans les solvants binaires. II-Étude des spectres de fluorescence. J. Chim. Phys. 66, 1474-1478.

13. Hochapfel, A., R. Journeaux and R. Viovy (1969) Existence et nature des formes agrégées de la chlorophylle $a$ dans les solvants binaires. I.-Étude des spectres d'absorption. J. Chim. Phys. 66, 1467-1473.

14. Vladkova, R. and S. Taneva (1988) Spectral characteristics of chlorophyll $a$ at different states of solvation. In Electromagnetic Fields and Biomembranes (Edited by $\mathrm{M}$. Markov and $\mathrm{M}$. Blank), pp. 267-271. Plenum Press, New York and London.

15. Agostiano, A., P. Cosma and M. Della Monica (1990) Spectroscopic and electrochemical characterization of chlorophyll $a$ in different water + organic solvent mixtures. Bioelectrochem. Bioenerg. 23, 311-324.

16. Uehara, K., M. Mimuro and M. Tanaka (1991) Spectroscopic studies of chlorophyll $a$ aggregates formed by aqueous dimethyl sulfoxide. Photochem. Photobiol. 53, 371-377.

17. Uehara, K., Y. Hioki and M. Mimuro (1993) The chlorophyll $a$ aggregate absorbing near $685 \mathrm{~nm}$ is selectively formed in aqueous tetrahydrofuran. Photochem. Photobiol. 58, 127-132.

18. Agostiano, A., M. Della Monica, G. Palazzo and M. Trotta (1993) Chlorophyll $a$ autoaggregation in water rich region. Biophys. Chem. 47, 193-202.

19. Balny, C., S. S. Brody and G. H. B. Hoa (1969) Absorption and fluorescence spectra of chlorophyll- $a$ in polar solvents as a function of temperature. Photochem. Photobiol. 9, 445-454.

20. Oba, T., M. Mimuro, Z.-Y. Wang, T. Nozawa, S. Yoshida and T. Watanabe (1997) Spectral characteristics and colloidal properties of chlorophyll $a^{\prime}$ in aqueous methanol. J. Phys. Chem. B 101, 3261-3268.

21. Gutman, V. (1978) The Donor-Acceptor Approach to Molecular Interactions. Plenum Press, New York.

22. Reichardt, C. (1979) Solvent Effects in Organic Chemistry. Verlag Chemie, Weinheim.

23. Renge, I. and R. Avarmaa (1985) Specific solvation of chlorophyll $a$ : solvent nucleophility, hydrogen bonding and steric effects on absorption spectra. Photochem. Photobiol. 42, 253-260.

24. Renge, I. V. and Ye. V. Bitova (1987) Solvation of chlorophylls by solvents modelling the protein environs. Biophysics 32, 403408.

25. Callahan, P. M. and T. M. Cotton (1987) Assignment of bacteriochlorophyll $a$ ligation state from absorption and resonance Raman spectra. J. Am. Chem. Soc. 109, 7001-7007.
26. Seely, G. R. and R. G. Jensen (1965) Effect of solvent on the spectrum of chlorophyll. Spectrochim. Acta 21, 1835-1845.

27. Dähne, S., W. Becker, M. Scholz, K. Teuchner, H. Lunch and H. Schneider (1980) Impuls Fluorometer auf Laserbasis. Feingerätetechnik. 29, 463-466.

28. Fujiwara, M. and M. Tasumi (1986) Resonance Raman and infrared studies on axial coordination to chlorophylls $a$ and $b$ in vitro. J. Phys. Chem. 90, 250-255.

29. Koyama, Y., Y. Umemoto, A. Akamatsu, K. Uehara and M. Tanaka (1986) Raman spectra of chlorophyll forms. J. Mol. Struct. 146, 273-287.

30. Åkerlöf, G. (1932) Dielectric constants of some organic solvent-water mixtures at various temperatures. J. Am. Chem. Soc. 54, 4125-4139.

31. Hasted, J. B. (1973) Dielectric properties. In Water. A Comprehensive Treatise, Vol. II, Water in Crystalline Hydrates; Aqueous Solutions of Simple Nonelectrolytes (Edited by F. Franks), Chapter 7, pp. 405-458. Plenum Press, New York.

32. Palm, V. A. (1977) The Fundamentals of the Quantitative Theory of Organic Reactions. Khimia Publishing House, Leningrad.

33. Reichardt, C. and K. Dimroth (1968) Lösungsmittel und empirische Parameter zur Charakterisierung ihrer Polarität. Fortschr. Chem. Forsch. 11, 1-73.

34. Köhler, W., P. Frölich and R. Radeglia (1969) Korrelation der chemischen Verschiebung der Wasserprotonen im NMR-Spektrum von Aceton-, 1,4-Dioxan-, und Tetrahydrofuran-WasserGemischen mit empirischen Parametern der Lösungsmittelpolarität. Z. Phys. Chem. 242, 220-224.

35. Vladkova, R. (1990) Influence of local environment on the spectral characteristics of chlorophylls. Ph.D. Thesis, Institute of Biophysics, Bulgarian Academy of Sciences, Sofia.

36. Szabo, A. G. and D. M. Rayner (1980) Fluorescence decay of tryptophan conformers in aqueous solution. J. Am. Chem. Soc. 102, 554-563.

37. Suppan, P. (1990) Solvatochromic shifts: the influence of the medium on the energy of electronic states. J. Photochem. Photobiol. A Chem. 50, 293-330.

38. Franks, F. (ed.) (1973) Water. A Comprehensive Treatise, Vol. II: Water in Crystalline Hydrates; Aqueous Solutions of Simple Nonelectrolytes. Plenum Press, New York.

39. Umetsu, M., Z.-Y. Wang, M. Kobayashi and T. Nozawa (1999) Interaction of photosynthetic pigments with various organic solvents. Magnetic circular dichroism approach and application to chlorosomes. Biochim. Biophys. Acta 1410, 19-31.

40. Vladkova, R. S., K. H. Mauring and I. V. Renge (1989) Specific solvation of chlorophyll $b$ : a site-selection study at 5 K. J. Photochem. Photobiol. B Biol. 3, 25-31.

41. Seely, G. R. and J. S. Connolly (1986) Fluorescence of photosynthetic pigments in vitro. In Light Emission by Plants and Bacteria (Edited by Govindjee), pp. 99-133. Academic Press, New York.

42. Oba, T., H. Furukawa, Z.-Y. Wang, T. Nozawa, M. Mimuro, H. Tamiaki and T. Watanabe (1998) Supramolecular structures of the chlorophyll $a^{\prime}$ aggregate and the origin of the diastereoselective separation of chlorophyll $a$ and $a^{\prime}$. J. Phys. Chem. B 102, 7882-7889.

43. Alfano, A. J., F. E. Lytle, M. S. Shoewell and F. K. Fong (1985) Excited singlet-state lifetimes of hydrated chlorophyll aggregates. J. Chem. Phys. 82, 758-764.

44. Kratky, C. and J. D. Dunitz (1977) Ordered aggregation states of chlorophyll $a$ and some derivatives. J. Mol. Biol. 113, 431442 .

45. Kadoshnikova, I. G. and B. A. Kiselev (1979) Colloidal solutions of chlorophyll. Electric charge of the particles. Biofizika 24, 811-814.

46. Heithier, H., K. Ballschmiter and H. Möhwald (1983) Liquidcrystalline phase transition of monomolecular layers of chlorophyll a. Photochem. Photobiol. 37, 201-205.

47. Ke, B. (1966) Some properties of chlorophyll monolayers and crystalline chlorophyll. In The Chlorophylls (Edited by L. P. Vernon and G. R. Seely), pp. 253-279. Academic Press, New York.

48. Cacace, M. G., E. M. Landau and J. J. Ramsden (1997) The 
Hofmeister series: salt and solvent effects on interfacial phenomena. Q. Rev. Biophys. 30, 241-277.

49. Collins, K. D. and M. W. Washabaugh (1985) The Hofmeister effect and the behaviour of water at interfaces. Q. Rev. Biophys. 18, 323-422.

50. Koynova, R., J. Brankov and B. Tenchov (1997) Modulation of lipid phase behavior by kosmotropic and chaotropic solutes. Experiment and thermodynamic theory. Eur. Biophys. J. 25, 261274.

51. Searle, G. F. W., C. J. Tredwell, J. Barber and G. Porter (1979) Picosecond time-resolved fluorescence study of chlorophyll organization and excitation energy distribution in chloroplasts from wild-type barley and a mutant lacking chlorophyll $b$. Biochim. Biophys. Acta 545, 496-507.

52. Garab, G., J. Kieleczawa, J. C. Sutherland, C. Busramante and G. Hind (1991) Organization of pigment-protein complexes into macrodomains in the thylakoid membranes of wild-type and chlorophyll $b$-less mutant of barley as revealed by circular dichroism. Photochem. Photobiol. 54, 273-281.

53. Baba, K., S. Itoh, G. Hastings and S. Hoshina (1996) Photoinhibition of Photosystem I electron transfer activity in isolated
Photosystem I preparations with different chlorophyll contents. Photosynth. Res. 47, 121-130.

54. Preiss, S., G. F. Peter, S. Anandan and J. P. Thornber (1993) The multiple pigment-proteins of the photosystem I antenna. Photochem. Photobiol. 57, 152-157.

55. Holzwarth, A. R. (1991) Excited-state kinetics in chlorophyll systems and its relationship to the functional organization of the photosystems. In Chlorophylls (Edited by H. Scheer), pp. 11251151. CRC Press, Boca Raton, FL.

56. Clayton, R. K. (1965) Molecular Physics of Photosynthesis, Chapter 12, pp. 149-164. Blaisdell Publ. Co., New York.

57. Ikegami, I. and S. Katoh (1991) Antenna chlorophyll $a$ has a structural role in stabilizing the functional conformation of $\mathrm{P}$ 700-chlorophyll-protein complexes. Biochim. Biophys. Acto 1059, 275-280.

58. Zhu, Y., B. L. Ramakrishna, P. I. van Noort and R. E. Blankenship (1995) Microscopic and spectroscopic studies of untreated and hexanol-treated chlorosomes from Chloroflexus aurantiacus. Biochim. Biophys. Acta 1232, 197-207.

59. Komsa-Penkova, R., R. Koynova, G. Kostov and B. G. Tenchov (1996) Thermal stability of calf skin collagen type I in salt solutions. Biochim. Biophys. Acta 1297, 171-181. 